Research

Open Access

\title{
Prevalence of endotoxemia after surgery and its association with ICU length of stay
}

\author{
Franco Valenza ${ }^{1,2}$, Lorella Fagnani², Silvia Coppola², Sara Froio², Francesca Sacconi², \\ Cecilia Tedesco², Micol Maffioletti², Marta Pizzocri2 ${ }^{2}$ Valentina Salice ${ }^{2}$, Maria Luisa Ranzi3, \\ Cristina Marenghi ${ }^{1}$ and Luciano Gattinoni, ${ }^{1,2}$
}

\begin{abstract}
1Dipartimento di Anestesia, Rianimazione (Intensiva e Subintensiva) e Terapia del Dolore, Fondazione IRCCS - "Ospedale Maggiore Policlinico Mangiagalli Regina Elena", Via Francesco Sforza 35, 20122, Milano, Italy

2Dipartimento di Anestesiologia Terapia Intensiva e Scienze Dermatologiche, Università degli Studi di Milano, Via Festa del Perdono 7, 20122, Milano, Italy

${ }^{3}$ Laboratorio Centrale di Analisi Chimico Cliniche e Microbiologiche; Fondazione IRCCS - "Ospedale Maggiore Policlinico Mangiagalli Regina Elena", Via Francesco. Sforza 35, 20122, Milano, Italy
\end{abstract}

Corresponding author: Franco Valenza, franco.valenza@unimi.it

Received: 7 Dec 2008 Revisions requested: 20 Jan 2009 Revisions received: 28 May 2009 Accepted: 29 Jun 2009 Published: 29 Jun 2009

Critical Care 2009, 13:R102 (doi:10.1186/cc7934)

This article is online at: http://ccforum.com/content/13/3/R102

(c) 2009 Valenza et al.; licensee BioMed Central Ltd.

This is an open access article distributed under the terms of the Creative Commons Attribution License (http://creativecommons.org/licenses/by/2.0), which permits unrestricted use, distribution, and reproduction in any medium, provided the original work is properly cited.

\begin{abstract}
Introduction The aim of this observational study was to investigate the prevalence of endotoxemia after surgery and its association with ICU length of stay.

Methods 102 patients admitted to a university ICU after surgery were recruited. Within four hours of admission, functional data were collected and APACHE II severity score calculated. Arterial blood samples were taken and endotoxemia was measured by chemiluminescence (Endotoxin Activity (EA)). Patients were stratified according to their endotoxin levels (low, intermediate and high) and according to their surgical procedures. Differences between endotoxin levels were assessed by ANOVA, accepting $P<0.05$ as significant. Data are expressed as mean $\pm S D$.
\end{abstract}

Results EA levels were low in $68(66 \%)$ patients, intermediate in $17(17 \%)$ and high in 17 (17\%). Age (61 \pm 17 years) and
APACHE II score $8.3 \pm 3.7(P=0.542)$ were not significantly different in the three EA groups. Functional parameters on admission were similar between EA groups: white blood cells $11093 \pm 4605$ cells $/ \mathrm{mm}^{3}(P=0.385)$, heart rate $76 \pm 16 \mathrm{bpm}$ $(P=0.898)$, mean arterial pressure $88.8 \pm 13.6 \mathrm{mmHg}(P=$ $0.576)$, lactate $1.18 \pm 0.77 \mathrm{mmol} / \mathrm{L}(P=0.370), \mathrm{PaO}_{2} / \mathrm{FiO}_{2}$ $383 \pm 109 \mathrm{mmHg}(P=0.474)$. Patients with high levels of $E A$ were characterized by longer length of stay in the ICU: $1.9 \pm 3.0$ days in the low EA group, $1.8 \pm 1.4$ days in intermediate and 5.2 \pm 7.8 days in high group $(P=0.038)$.

Conclusions $17 \%$ of our patients were characterized by high levels of endotoxemia as assessed by EA assay, despite their low level of complexity on admission. High levels of endotoxin were associated with a longer ICU length of stay.

\section{Introduction}

Endotoxin is a constituent of the cell wall of Gram-negative bacteria capable of inducing potent inflammatory response in the host [1,2]. Isolated and purified from the wall of several Gram-negative bacteria, it has been used to investigate many aspects of the immuno-inflammatory response of sepsis through inoculation in the laboratory animal $[3,4]$ or in humans [5-7]. However, endotoxin has also been documented in clini- cal scenarios such as trauma or burn injury [8-10]. Rather than a manifestation of exogenous infection, translocation of lipopolysaccharide across the intestinal membrane when permeability is increased is the putative mechanism of these forms of endotoxemia [11,12].

Patients undergoing surgery may have direct shedding of lipopolysaccharide into the circulation via manipulation of 
infected surgical sites, violation of natural barriers such as bowel resection, contamination from the environment, or via the use of invasive devices. Meanwhile, postural changes, blood loss, and vasoplegia all cause relative or absolute hypoperfusion that may favor bacterial translocation. Buttenschoen and colleagues have in fact shown that major abdominal surgery is associated with transient endotoxemia [13,14]. However, while the likelihood of endotoxemia might be straightforward in major abdominal surgery, less is known in other surgical procedures, apart from cardiopulmonary bypass $[15,16]$.

We studied the prevalence of endotoxemia in a population of patients admitted to an intensive care unit (ICU) after surgery and the relation between endotoxemia and their outcome.

\section{Materials and methods}

The study was approved by our institution ethics committee, and informed consent was obtained from all patients. Adult patients admitted to the ICU of our institution were recruited for the study unless they were transferred from another ICU, had no arterial line in place, or were on chronic dialysis.

On admission and the next morning, clinical history and laboratory data were taken. Cardio-respiratory variables were recorded and Acute Physiology and Chronic Health Evaluation (APACHE) II score was calculated [17]. Systemic Inflammatory Reaction Syndrome (SIRS) was considered to be present when at least two of these criteria were met: temperature above $38^{\circ} \mathrm{C}$ or below $36^{\circ} \mathrm{C}$, heart rate of more than 90 beats/ min, respiratory rate of more than 20 breaths/min or partial pressure of carbon dioxide of less than $32 \mathrm{mmHg}$, or white blood cell count above $12,000 \mathrm{~mm}^{3}$ or below $4000 \mathrm{~mm}^{3}$ [18]. Within four hours after admission blood was withdrawn for Endotoxin Activity (EA) assay. During the course of the ICU stay blood and other biologic specimens were collected on a clinical basis and sent to the microbiologic laboratory of the institution for microorganism detection. Length of stay and mortality of both ICU and hospital were calculated. Clinicians were unaware of the results of the EA assay throughout patient's ICU and hospital stay.

\section{Endotoxin activity assay}

The EA assay has been described in detail previously [19]. Briefly, the method allows the measurement of EA as a function of each patient's neutrophil chemiluminescence's activity (on a scale from 0 to 1). An EA level of 0.4 is approximately equivalent to an endotoxin concentration of 25 to $50 \mathrm{pg} / \mathrm{mL}$, and a level of 0.6 equivalent to 100 to $200 \mathrm{pg} / \mathrm{mL}$. A $2 \mathrm{ml} \mathrm{sam-}$ ple of whole blood was drawn through an indwelling arterial line into an endotoxin-free blood collection tube (Vacutainer systems; Becton Dickinson, Franklin Lakes, NJ, USA). Blood samples were maintained at room temperature and assayed within 30 minutes of collection. To assay levels of endotoxin, a $10 \mu \mathrm{l}$ aliquot of whole blood was placed in each of three tubes containing luminol buffer ( $300 \mu \mathrm{l} /$ tube). The control tube contained blood and buffer only, whereas a positive control contained a maximum stimulatory concentration of endotoxin (2 $\mathrm{ng} / \mathrm{ml}$ ); the final tube contained the test sample. All three tubes were incubated at $37^{\circ} \mathrm{C}$ for five minutes and assayed in duplicate. Chemiluminescence was initiated by the addition of 20 $\mu \mathrm{l} /$ tube human complement opsonized zymosan. Continuous measurements were made of light emissions at 30-second intervals over a total period of 20 minutes in a reciprocating tube luminometer (Autolumat LB 953; E. G. \& G. Berthold, Wildbad, Germany). Quality control assays were performed on a 1:1 ratio basis (i.e. one control every sample measured). Based on the results obtained, samples were considered adequate if the coefficient of variation between duplicates was lower than 15\% if EA level was below 0.2 and $30 \%$ if it was above 0.2 .

\section{Statistical analysis}

A descriptive analysis was first conducted on the entire population. Patients were then stratified according to the EA results into the following groups: Iow $(E A<0.4)$, intermediate (EA 0.4 to $<0.6)$ and high $(E A \geq 0.6)$. To compare continuous variables on admission such as age, APACHE II score, and functional parameters based on both surgical or EA stratification, oneway analysis of variance was used and all pairwise multiple comparisons were assessed by Student Newman-Keuls test. If the normality test (Kolmogorov-Smirnov) failed, data were analysed by Kruskal-Wallis one-way analysis of variance and for all pairwise multiple comparisons procedures Dunn's method was used. Functional parameters at entry and on the next morning were analyzed according to EA stratification by means of two-way analysis of variance. This was also used to assess the interaction between EA levels and the type of surgery in determining ICU and hospital length of stay. For statistical purposes, patients were stratified according to the different kind of surgical procedures they underwent into major surgery and other procedures. Data are presented as mean \pm standard deviation, unless otherwise specified. Statistical significance was accepted as $P<0.05$. The Sigma Stat for Windows version 3.11 (Systat Software Inc, Pont Richmond, CA, USA) was used.

\section{Results}

A total of 122 patients were recruited for the study. All patients had their EA level measured on admission. However, 20 patients were excluded from analysis: 17 because variation of coefficients were out of the accepted range, two because the calculation of EA level was unreliable (value $>1$ ), and one because quality control failed. Therefore, a total of 102 patients were considered.

Out of the 102 patients included in the study, 27 underwent thoracic surgical procedures including 25 resective procedures and 2 decortications; 27 patients underwent abdominal procedures including gastric, intestine, and colon rectum sur- 
gery; 20 obese patients underwent gastric banding; 11 patients underwent hepatectomies; 7 underwent urological proceures including 3 procedures on the bladder, 3 prostatectomies, and 1 nephroureterectomy. The remaining 10 patients underwent procedures other then those above mentioned including three timectomies, three femoral bone fracture repair, two median abdominal wall laparocele synthesis, and two tiroidectomies. Patients were scheduled for elective post-operative ICU monitoring. Five patients were admitted because of intra-operative complications. Patients demographics were similar between surgical groups except for obese patients who underwent gastric banding that were younger $(P<0.05)$ and had lower APACHE II scores $(P<$ 0.05). Data are shown on Table 1.

Median EA level was 0.282 (25\% 0.190, 75\% 0.462). When stratified according to EA levels, $68(66 \%)$ had normal values, $17(17 \%)$ had intermediate, and 17 (17\%) had high levels. As shown in Figure 1, patients with high EA levels $(>0.6)$ on admission were characterized by a longer ICU length of stay $(P=0.038)$; in hospital length of stay was not different between groups $(P=0.387)$. In patients with high EA activity functional parameters were similar on admission to the other EA stratification groups except for a somewhat higher temperature. However, in contrast to patients without high EA levels, the number of SIRS criteria, white blood cell count, and lactate levels did not improve over time from the first day. Data are shown on Table 2. Patients who underwent major surgery (abdominal or thoracic procedures) and presented to the ICU with higher EA levels were characterized by significantly longer ICU length of stay (Figure 2). These patients were characterized intraoperatively by a slightly worse oxygenation despite a more aggressive ventilatory management; the hemodynamic status was similar between EA stratification groups.
Data are shown on Table 3. Complications that resulted in longer ICU stay included: respiratory insufficiency $(n=11)$, septic shock $(n=2)$, caridac arrhythmia $(n=3)$, and pneumonia $(n=1)$. A total of 152 specimens from 41 patients were sent to the microbiologic laboratory during the ICU stay. Of these, 46 were positive in a total of 13 patients. The characteristics of these patients are summarised in Table 4.

\section{Discussion}

This observational study investigates the prevalence of endotoxemia in a population of patients admitted to the ICU after surgery and evaluates the association between endotoxin levels and outcome. We found that $17 \%$ of the patients had levels of endotoxin higher than normal on admission despite the low level of complexity, and that patients with high endotoxin levels had longer ICU length of stay.

To detect endotoxemia we chose to use the EA assay as opposed to the more classic limulus-amebocyte-lysate (LAL) test $[20,21]$ This method is based on the detection of enhanced respiratory burst activity in neutrophils following their priming by complexes of endotoxin and a specific antiendotoxin antibody [19]. The method allows the expression of EA as a function of each patient's neutrophil chemiluminescence's activity (on a scale from 0 to 1 ). The technique has been validated against the LAL test [22], and has been recently used in a multicenter trial to assess endotoxin prevalence in a mixed surgical/medical ICU cohort of patients recruited across North America and Europe [23]. According to this method, most of the patients admitted to the ICU after surgery had normal levels of endotoxin. However, 17 out of 102 had higher than normal levels of endotoxin despite their low level of complexity (APACHE score) These data confirm previous observations that circulating endotoxin is a common find-

Table 1

Characteristics of the study population

\begin{tabular}{|c|c|c|c|c|c|c|c|}
\hline & All & Thoracic & Abdominal & Obesity & Hepatic & Urological & Other \\
\hline N. of patients & 102 & 27 & 27 & 20 & 11 & 7 & 10 \\
\hline Age (years) & $62 \pm 17$ & $67 \pm 8$ & $69 \pm 17$ & $40 \pm 9$ & $58 \pm 18$ & $64 \pm 14$ & $69 \pm 17$ \\
\hline Surgery (min) & $178 \pm 95$ & $166 \pm 64$ & $200 \pm 111$ & $121 \pm 38$ & $267 \pm 106$ & $297 \pm 80$ & $146 \pm 103$ \\
\hline Unscheduled (n) & 5 & - & 2 & - & - & - & 3 \\
\hline APACHE II score & $8.4 \pm 4$ & $9.1 \pm 3$ & $9.7 \pm 4$ & $4.7 \pm 2$ & $8.4 \pm 5$ & $9.0 \pm 3$ & $9.3 \pm 4$ \\
\hline EA activity & $0,3 \pm 0.3$ & $0.4 \pm 0.2$ & $0.3 \pm 0.2$ & $0.4 \pm 0.2$ & $0.3 \pm 0.3$ & $0.3 \pm 0.3$ & $0.4 \pm 0.1$ \\
\hline LOS ICU (days) & 1 (1 to 2$)$ & 1 (1 to 2 ) & 1 (1 to 4.7$)$ & $1(1$ to 1$)$ & 1 (1 to 1$)$ & 1 (1 to 1$)$ & 1 (1 to 2$)$ \\
\hline Mortality ICU (n) & 3 & - & 2 & - & - & - & - \\
\hline LOS hosp (days) & $8(5-11)$ & $8.5(6-13)$ & $10(7-16)$ & $4(4-5)$ & $8.0(6-10)$ & $12(9-13)$ & $6.5(5-10)$ \\
\hline Mortality hosp (n) & 1 & 1 & - & - & - & - & - \\
\hline
\end{tabular}

Characteristics of the study population are shown. Intensive care unit (ICU) and hospital length of stay (LOS) are presented as median and interquartile ranges. Other data are presented as mean \pm standard deviation.

$\mathrm{APACHE}=$ Acute Physiology and Chronic Health Evaluation; $\mathrm{EA}=$ endotoxin activity. 
Figure 1

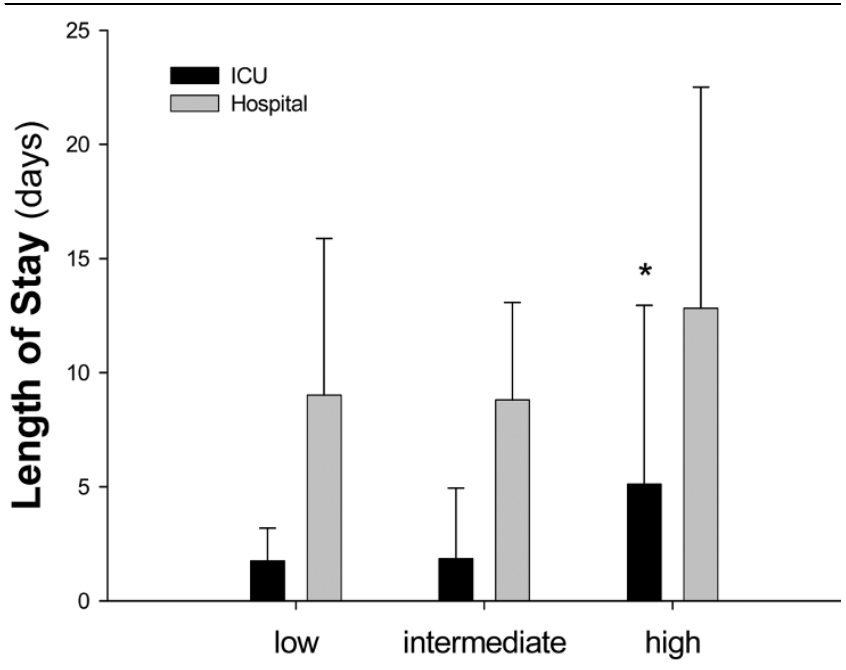

\section{Endotoxin Activity}

Intensive care unit and hospital length of stay according to endotoxin activity stratification. Intensive care unit (ICU) = black columns; Hospital = gray columns

ing in ICU patients [23], but add to the knowledge on endotoxin prevalence in post-operative patients. In fact, while endotoxemia in patients undergoing major abdominal procedures has been previously shown [13,14], our observation extend to other kind of surgical interventions less likely to be characterized by endotoxemia.

Figure 2



Intensive care unit length of stay according to endotoxin activity stratification within surgical stratification. White columns represent data from patients with high endotoxin activity (EA) levels, while dashed columns refer to patients with intermediate or low EA levels.
Subjects with high EA levels had a longer ICU length of stay and a trend towards longer hospital length of stay (Figure 1). Interestingly, functional parameters on admission were almost normal and similar between groups of patients stratified by EA levels (Table 2). Subjects with high EA on admission, despite being similar to the other groups with respect to functional data, demonstrated that white blood cell count, SIRS criteria, and lactate did not significantly decrease on the morning after admission. Whether this was indicative of an ongoing inflammatory process or adequacy of perfusion is difficult to determine. The role of microbial-derived endotoxin appears to play a minor role in our study: the clinical suspicion of infection during ICU stay was brought on only in a few subjects and even less had proven infection during the course of their ICU stay (Table 4). Moreover, the intraoperative hemodynamic variables were similar between EA stratification groups (Table 3). However, the prevalence of high endotoxin levels in patients who underwent thoracic surgery and the trend towards a relative hypoxemia despite more aggressive ventilatory management in patients with high EA levels is of interest. Both hypoxemia [24] and mechanical ventilation [25] are related to endotoxemia, even if we cannot exclude the potential higher prevalence of cigarette smokers in the thoracic group [26]. Except for obese patients that represent a unique topology, patients that underwent thoracic and abdominal procedures were similar to the others, with respect to age, APACHE score, and functional data at ICU admission. This suggests that measurement of EA is a potential tool to stratify patients to more aggressive care or to allocate resources in dynamic ICUs recruiting post-operative patients for routine monitoring. Whether EA stratification is useful only for abdominal and thoracic procedures cannot be determined from our data: the number of subjects does not allow for multivariate analysis. Moreover, we do not have EA data prior to surgery in order to discriminate between patients who presented to the operating room with pre-existing endotoxemia that might have persisted after the surgical procedure itself. These are interesting aspects that need further attention.

There are limitations to our study. Because of logistical reasons measurements were available only during the week days: this may have introduced a selection bias. As discussed above, pre-operative evidence of endotoxemia is lacking: this would have added to the interpretation of the data. Moreover, the number of patients recruited is not high enough to generalize our results to a wider ICU population.

\section{Conclusions}

In this study we have investigated the prevalence of endotoxemia in a population of patients admitted to an ICU after surgery. A number of patients were characterized by high levels of endotoxemia, as assessed by EA assay, despite their low level of complexity on admission. High levels of endotoxin were associated with a longer ICU length of stay, particularly in patients who underwent major surgery. 
Table 2

\begin{tabular}{|c|c|c|c|c|}
\hline & & Low & Intermediate & High \\
\hline \multirow[t]{2}{*}{ Ventilated patients } & Admission & $62 / 68(91 \%)$ & $16 / 17(94 \%)$ & $17 / 17(100 \%)$ \\
\hline & Day 1 & $6 / 68(9 \%)^{*}$ & $1 / 17(6 \%)^{\star}$ & $1 / 17(6 \%)^{\star}$ \\
\hline \multirow[t]{2}{*}{ Tidal volume (I/min) } & Admission & $6.5 \pm 1.8$ & $6.4 \pm 1.2$ & $7.3 \pm 1.9$ \\
\hline & Day 1 & I & I & I \\
\hline \multirow[t]{2}{*}{ Respiratory rate (atti/minuto) } & Admission & $11 \pm 4$ & $11 \pm 2$ & $12 \pm 7$ \\
\hline & Day 1 & $18 \pm 5^{\star}$ & $19 \pm 5^{\star}$ & $16 \pm 4^{\star}$ \\
\hline \multirow[t]{2}{*}{$\mathrm{PaO}_{2} / \mathrm{FiO}_{2}(\mathrm{mmHg})$} & Admission & $379 \pm 111$ & $413 \pm 113$ & $372 \pm 96$ \\
\hline & Day 1 & $329 \pm 62^{*}$ & $330 \pm 46^{\star}$ & $299 \pm 83^{\star}$ \\
\hline \multirow[t]{2}{*}{$\mathrm{PaCO}_{2}(\mathrm{mmHg})$} & Admission & $38.6 \pm 4.9$ & $35.1 \pm 5.6^{\#}$ & $37.7 \pm 5.0$ \\
\hline & Day 1 & $39.9 \pm 4.7$ & $39.3 \pm 5.1^{*}$ & $38.8 \pm 4.1$ \\
\hline \multirow[t]{2}{*}{$\mathrm{pH}$ arterial blood } & Admission & $7.41 \pm 0.05$ & $7.42 \pm 0.06$ & $7.39 \pm 0.06$ \\
\hline & Day 1 & $7.43 \pm 0.03$ & $7.43 \pm 0.03$ & $7.43 \pm 0.04$ \\
\hline \multirow[t]{2}{*}{ Lactate $(\mathrm{mmol} / \mathrm{l})$} & Admission & $1.12 \pm 0.57$ & $1.23 \pm 0.47$ & $1.40 \pm 1.39$ \\
\hline & Day 1 & $0.79 \pm 0.38^{*}$ & $0.81 \pm 0.37^{\star}$ & $0.89 \pm 0.57$ \\
\hline \multirow[t]{2}{*}{ Heart rate $(\mathrm{bpm})$} & Admission & $76 \pm 16$ & $75 \pm 17$ & $77 \pm 18$ \\
\hline & Day 1 & $82 \pm 15^{\star}$ & $80 \pm 12$ & $84 \pm 15$ \\
\hline \multirow[t]{2}{*}{ Mean arterial pressure $(\mathrm{mmHg})$} & Admission & $88 \pm 13$ & $87 \pm 13$ & $92 \pm 17$ \\
\hline & Day 1 & $91 \pm 12$ & $94 \pm 13$ & $93 \pm 16$ \\
\hline \multirow[t]{2}{*}{ Central venous pressure $(\mathrm{mmHg})$} & Admission & $7.5 \pm 2.5$ & $6.3 \pm 2.9$ & $7.5 \pm 2.2$ \\
\hline & Day 1 & $6.1 \pm 2.6$ & $6.1 \pm 2.5$ & $6.1 \pm 2.7$ \\
\hline \multirow[t]{2}{*}{ Hemoglobin (g/dl) } & Admission & $12.0 \pm 3.5$ & $12.4 \pm 1.8$ & $12.4 \pm 1.6$ \\
\hline & Day 1 & $11.3 \pm 1.6$ & $11.5 \pm 1.7$ & $12.0 \pm 1.3$ \\
\hline \multirow[t]{2}{*}{ Creatinine (mg/dl) } & Admission & $0.99 \pm 0.92$ & $1.06 \pm 0.68$ & $0.89 \pm 0.37$ \\
\hline & Day 1 & $1.04 \pm 1.12$ & $1.05 \pm 0.47$ & $0.85 \pm 0.27$ \\
\hline \multirow[t]{2}{*}{ Azotemia (mg/dl) } & Admission & $36 \pm 24$ & $40 \pm 21$ & $37 \pm 21$ \\
\hline & Day 1 & $37 \pm 27$ & $41 \pm 24$ & $36 \pm 25$ \\
\hline \multirow[t]{2}{*}{ Glycemia (mg/dl) } & Admission & $134 \pm 30$ & $134 \pm 25$ & $132 \pm 35$ \\
\hline & Day 1 & $110 \pm 29^{*}$ & $111 \pm 23^{*}$ & $105 \pm 21^{*}$ \\
\hline \multirow[t]{2}{*}{ Sodium ( $\left.\mathrm{Na}^{+} ; \mathrm{mEq} / \mathrm{l}\right)$} & Admission & $137.5 \pm 2.5$ & $137.1 \pm 2.2$ & $137.8 \pm 2.1$ \\
\hline & Day 1 & $137.9 \pm 2.7$ & $138.4 \pm 3.5$ & $138.1 \pm 2.7$ \\
\hline \multirow[t]{2}{*}{ Potassium ( $\left.\mathrm{K}^{+} ; \mathrm{mEq} / \mathrm{l}\right)$} & Admission & $3.9 \pm 0.5$ & $3.9 \pm 0.5$ & $3.9 \pm 0.4$ \\
\hline & Day 1 & $4.1 \pm 0.3^{*}$ & $4.0 \pm 0.4^{\star}$ & $3.9 \pm 0.4$ \\
\hline \multirow[t]{2}{*}{ Temperature $\left({ }^{\circ} \mathrm{C}\right)$} & Admission & $35.2 \pm 0.9$ & $34.5 \pm 0.9$ & $35.4 \pm 1.2^{\#}$ \\
\hline & Day 1 & $36.6 \pm 0.6$ & $36.7 \pm 0.5$ & $36.8 \pm 0.5$ \\
\hline \multirow[t]{2}{*}{ WBC $\left(10^{3} / \mathrm{mm}^{3}\right)$} & Admission & $10.8 \pm 4.2$ & $12.5 \pm 5.5$ & $10.8 \pm 5.1$ \\
\hline & Day 1 & $9.4 \pm 3.0^{\star}$ & $10.4 \pm 4.0$ & $10.2 \pm 2.7$ \\
\hline \multirow[t]{2}{*}{ SIRS criteria } & Admission & $1.4 \pm 0.7$ & $1.8 \pm 0.8$ & $1.4 \pm 0.9$ \\
\hline & Day 1 & $0.9 \pm 0.9^{*}$ & $1.3 \pm 1.1^{\star}$ & $0.9 \pm 0.8$ \\
\hline
\end{tabular}

Ventilatory and functional parameters collected within four hours of admission to the intensive care unit (Admission) and the morning after (Day 1) are shown in the table. Patients were stratified according to their endotoxin activity levels on admission. ${ }^{*} P<0.05$ Admission vs Day 1 ; \# $p<$ 0.05 between EA stratification groups. $\mathrm{FiO}_{2}=$ fraction of inspired yoghurt; $\mathrm{PaCO}_{2}=$ partial pressure of arterial carbon dioxide; $\mathrm{PaO}_{2}=$ partial pressure of arterial oxygen; SIRS = Systemic Inflammatory Reaction Syndrome; WBC = white blood cell. 
Critical Care Vol 13 No 3 Valenza et al.

Table 3

Intra-operative variables of the patients who underwent major surgery

\begin{tabular}{|c|c|c|c|}
\hline & Low & Intermediate & High \\
\hline Number of patients ( $n$ ) & 34 & 10 & 10 \\
\hline Age (years) & $69 \pm 15$ & $67 \pm 8$ & $67 \pm 12$ \\
\hline Duration of surgery (min) & $174 \pm 101$ & $183 \pm 73$ & $189 \pm 86$ \\
\hline Arterial pressure - OR $(\mathrm{mmHg})$ & $121 \pm 11$ & $118 \pm 13$ & $123 \pm 11$ \\
\hline Arterial pressure - Preop $(\mathrm{mmHg})$ & $136 \pm 17$ & $140 \pm 14$ & $135 \pm 11$ \\
\hline $\mathrm{pH}$ & $7.388 \pm 0.05$ & $7.420 \pm 0.05$ & $7.392 \pm 0.04$ \\
\hline BE & $-0.9 \pm 2.5$ & $-0.6 \pm 1.9$ & $-0.4 \pm 2.4$ \\
\hline Urine output $(\mathrm{ml} / \mathrm{h})$ & $239 \pm 193$ & $331 \pm 346$ & $181 \pm 98$ \\
\hline Cristalloids $(\mathrm{mL})$ & $3045 \pm 1590$ & $2895 \pm 917$ & $3078 \pm 900$ \\
\hline Colloids (mL) & $580 \pm 280$ & $533 \pm 57$ & $500 \pm 0$ \\
\hline Blood transfusion ( $\mathrm{n}$ ) & 5 & 1 & 1 \\
\hline $\mathrm{PaO}_{2} / \mathrm{FiO}_{2}(\mathrm{mmHg})$ & $307 \pm 141$ & $275 \pm 193$ & $243 \pm 145$ \\
\hline Tidal volume $(\mathrm{mL})$ & $679 \pm 102$ & $667 \pm 129$ & $715 \pm 109$ \\
\hline Respiratory rate $(\mathrm{bpm})$ & $9.9 \pm 1.5$ & $9.8 \pm 0.6$ & $9.9 \pm 1.1$ \\
\hline Peak airway pressure $\left(\mathrm{cmH}_{2} \mathrm{O}\right)$ & $23.8 \pm 6.3$ & $20.8 \pm 5.9$ & $24.3 \pm 6.2$ \\
\hline PEEP $\left(\mathrm{cmH}_{2} \mathrm{O}\right)$ & $2.4 \pm 2.3$ & $0.9 \pm 2.1$ & $3.5 \pm 2.4$ * \\
\hline Invasiveness (n) & $5.1 \pm 1.1$ & $5.4 \pm 0.8$ & $5.4 \pm 0.8$ \\
\hline Contaminated surgery $(\mathrm{n})$ & 2 & - & - \\
\hline
\end{tabular}

Intra-operative variables of the patients who underwent abdominal or thoracic surgery are presented. ${ }^{*} P<0.05$ analysis of variance. Arterial pressure $-\mathrm{OR}=$ mean systolic arterial pressure recorded during the intervention; Arterial pressure - Preop $=$ systolic arterial pressure taken at the time of the preoperative evaluation; $\mathrm{BE}=$ base excess; $\mathrm{FiO}_{2}=$ fraction of inspired yoghurt; $\mathrm{PaO}_{2}=$ partial pressure of arterial oxygen; $\mathrm{PEEP}=$ positive end-expiratory pressure. Invasiveness = sum of invasive procedure including tracheal tube, periferal vein, central vein, arterial line, nasogastric tube, bladder catheter. 
Table 4

\begin{tabular}{|c|c|c|c|c|c|c|c|c|c|c|c|}
\hline EA level & Age & Surgery & APACHE & SIRS & Gram + & Gram - & Other & Time & $\mathrm{ICU}$ & Hosp & Alive \\
\hline 0.140 & 77 & $A$ & 11 & 2 & & Klebsiella & & Late & 4 & 20 & $Y$ \\
\hline 0.446 & 50 & $\mathrm{~T}$ & 6 & 2 & & & Candida & Late & 1 & 6 & $Y$ \\
\hline 0.432 & 73 & $\mathrm{O}$ & 13 & 2 & & Contaminants & & Late & 2 & 6 & $Y$ \\
\hline 0.125 & 78 & $A$ & 9 & 2 & & Pseudomonas & & Late & 24 & 26 & $Y$ \\
\hline 0.333 & 71 & $A$ & 9 & 1 & S. epidermidis & & & Early & 1 & 12 & $Y$ \\
\hline 0.235 & 43 & $A$ & 10 & 2 & S. aureus & & & Early & 2 & 12 & $Y$ \\
\hline 0.330 & 90 & $\mathrm{O}$ & 11 & 2 & & Enterobacter & & Early & 1 & 32 & $Y$ \\
\hline 0.191 & 72 & $A$ & 10 & 2 & S. aureus & & & Early & 8 & 19 & $Y$ \\
\hline 0.558 & 59 & $\mathrm{~T}$ & 4 & 2 & & Pseudomonas & & Early & 5 & 9 & $Y$ \\
\hline 0.498 & 36 & $\mathrm{O}$ & 3 & 3 & Enterococcus & & & Early & 5 & 19 & $Y$ \\
\hline 0.750 & 78 & A & 7 & 1 & & Pseudomonas & & Early & 28 & - & $\mathrm{N}$ \\
\hline 0.825 & 67 & A & 13 & 3 & & Morganella M & & Late & 22 & - & $\mathrm{N}$ \\
\hline 0.740 & 76 & $\mathrm{~T}$ & 8 & 1 & & Klebsiella & & Late & 7 & 29 & $Y$ \\
\hline
\end{tabular}

Table includes endotoxin activity (EA) level, age, type of surgery $(A=$ abdominal, $T=$ thoracic, $O=$ other), Acute Physiology and Chronic Health Evaluation (APACHE) score, numbers of Systemic Inflammatory Reaction Syndrome (SIRS) criteria met at the time of intensive care unit (ICU) admission, strain of microrganisms isolated, whether the microbiological samples were collected early after the admission ( $E$ - within three days) or at a later time (L); the ICU and hospital length of stay, survival.

\section{Key messages}

- Endotoxemia is detectable in patients admitted to the ICU after surgery.

- High levels of endotoxemia are associated with longer ICU length of stay.

\section{Competing interests}

The authors declare that they have no competing interests.

\section{Authors' contributions}

FV conceived the study, collected and analysed the data, and wrote the manuscript. LF collected and analysed the data, and wrote the manuscript. SC, SF, FS, CT, MM, MP, and VS collected the data and performed analysis. MLR collected the microbiologic data. CM collected the data. LG wrote the manuscript.

\section{Acknowledgements}

The authors would like to thank Spectral Diagnostics Inc. for providing the instrumentation and the reagents to run the endotoxin activity assays. This study was funded by Fondazione Ospedale Maggiore, Mangiagalli e Regina Elena - IRCCS.

\section{References}

1. Carswell EA, Old LJ, Kassel RL, Green S, Fiore N, Williamson B: An endotoxin-induced serum factor that causes necrosis of tumors. Proc Natl Acad Sci USA 1975, 72:3666-3670.

2. Ulevitch RJ, Tobias PS: Recognition of gram-negative bacteria and endotoxin by the innate immune system. Curr Opin Immunol 1999, 11:19-22.

3. Emerson TE Jr, Gill CC: Effects of slow intravenous endotoxin infusion on hemodynamics and survival in dogs. $J$ Appl Physiol 1967, 22:874-877.

4. Natanson C, Eichenholz PW, Danner RL, Eichacker PQ, Hoffman WD, Kuo GC, Banks SM, MacVittie TJ, Parrillo JE: Endotoxin and tumor necrosis factor challenges in dogs simulate the cardiovascular profile of human septic shock. J Exp Med 1989, 169:823-832. 
5. Colucci M, Balconi G, Lorenzet R, Pietra A, Locati D, Donati MB, Semeraro N: Cultured human endothelial cells generate tissue factor in response to endotoxin. J Clin Invest 1983, 71:1893-1896.

6. Suffredini AF, Fromm RE, Parker MM, Brenner M, Kovacs JA, Wesley RA, Parrillo JE: The cardiovascular response of normal humans to the administration of endotoxin. N Engl J Med $1989,321: 280-287$.

7. Taveira da Silva AM, Kaulbach HC, Chuidian FS, Lambert DR, Suffredini AF, Danner RL: Brief report: shock and multiple-organ dysfunction after self-administration of Salmonella endotoxin. N Engl J Med 1993, 328:1457-1460.

8. Munster AM, Winchurch RA, Thupari JN, Ernst CB: Reversal of postburn immunosuppression with low-dose polymyxin B. J Trauma 1986, 26:995-998.

9. Winchurch RA, Thupari JN, Munster AM: Endotoxemia in burn patients: levels of circulating endotoxins are related to burn size. Surgery 1987, 102:808-812.

10. Kelly JL, O'Sullivan C, O'Riordain M, O'Riordain D, Lyons A, Doherty J, Mannick JA, Rodrick ML: Is circulating endotoxin the trigger for the systemic inflammatory response syndrome seen after injury? Ann Surg 1997, 225:530-541.

11. LeVoyer T, Cioffi WG Jr, Pratt L, Shippee R, McManus WF, Mason AD Jr, Pruitt BA Jr: Alterations in intestinal permeability after thermal injury. Arch Surg 1992, 127:26-29.

12. Munster AM, Smith-Meek M, Dickerson C, Winchurch RA: Translocation. Incidental phenomenon or true pathology? Ann Surg 1993, 218:321-326.

13. Buttenschoen $K$, Buttenschoen DC, Berger D, Vasilescu C, Schafheutle S, Goeltenboth B, Seidelmann M, Beger HG: Endotoxemia and acute-phase proteins in major abdominal surgery. $A m J$ Surg 2001, 181:36-43.

14. Buttenschoen K, Schneider ME, Utz K, Kornmann M, Beger HG, Carli BD: Effect of major abdominal surgery on endotoxin release and expression of Toll-like receptors 2/4. Langenbecks Arch Surg 2009, 394:293-302.

15. Boelke E, Storck M, Buttenschoen K, Berger D, Hannekum A: Endotoxemia and mediator release during cardiac surgery. Angiology 2000, 51:743-749.

16. Jansen PG, Te VH, Oudemans-Van Straaten HM, Bulder ER, Van Deventer SJ, Sturk A, Eijsman L, Wildevuur CR: Perfusion-related factors of endotoxin release during cardiopulmonary bypass. Eur J Cardiothorac Surg 1994, 8:125-129.

17. Knaus WA, Draper EA, Wagner DP, Zimmerman JE: APACHE II: a severity of disease classification system. Crit Care Med 1985, 13:818-829.

18. Members of the American College of Chest Physicians/Society of Critical Care Medicine Consensus Conference: American College of Chest Physicians/Society of Critical Care Medicine Consensus Conference: definitions of sepsis and organ failure and guidelines for the use of innovative therapies in sepsis. Crit Care Med. 1992, 20:864-874.

19. Romaschin AD, Harris DM, Ribeiro MB, Paice J, Foster DM, Walker PM, Marshall JC: A rapid assay of endotoxin in whole blood using autologous neutrophil dependent chemiluminescence. J Immunol Methods 1998, 212:169-185.

20. Levin J, Bang FB: Clottable protein in Limulus; its localization and kinetics of its coagulation by endotoxin. Thromb Diath Haemorrh 1968, 19:186-197.

21. Tamura H, Tanaka S, Obayashi T, Yoshida M, Kawai T: A new sensitive method for determining endotoxin in whole blood. Clin Chim Acta 1991, 200:35-42.

22. Marshall JC, Walker PM, Foster DM, Harris D, Ribeiro M, Paice J, Romaschin AD, Derzko AN: Measurement of endotoxin activity in critically ill patients using whole blood neutrophil dependent chemiluminescence. Crit Care 2002, 6:342-348.

23. Marshall JC, Foster D, Vincent JL, Cook DJ, Cohen J, Dellinger RP Opal S, Abraham E, Brett SJ, Smith T, Mehta S, Derzko A Romaschin A: Diagnostic and prognostic implications of endotoxemia in critical illness: results of the MEDIC study. J Infect Dis 2004, 190:527-534.

24. Gaffin SL, Brock-Utne JG, Zanotti A, Wells MT: Hypoxia-induced endotoxemia in primates: role of reticuloendothelial system function and anti-lipopolysaccharide plasma. Aviat Space Environ Med 1986, 57:1044-1049.

25. Nahum A, Hoyt J, Schmitz L, Moody J, Shapiro R, Marini JJ: Effect of mechanical ventilation strategy on dissemination of intrat- racheally instilled Escherichia coli in dogs. Crit Care Med 1997, 25:1733-1743

26. Hasday JD, Bascom R, Costa JJ, Fitzgerald T, Dubin W: Bacterial endotoxin is an active component of cigarette smoke. Chest $1999,115: 829-835$. 